\title{
Simulation and study of strength properties of rocks by measuring characteristics during the blast holes drilling
}

\author{
Andrey Regotunov ${ }^{1 *}$ and Rudolf Sukhov ${ }^{1}$ \\ ${ }^{1}$ Federal state budget-funded science establishment Institute of Mining of Ural branch of Russian \\ Academy of Science, Ekaterinburg, Russia.
}

\begin{abstract}
The article shows the results of the development of a method for obtaining information on the strength properties of an massif in the process of drilling of blast holes. This method is developed for open-cast mining and serves to increase the effectiveness of mass explosions. The order of operations is shown and the equipment is described for obtaining the necessary measured characteristics for the subsequent simulation of the distribution of rocks in the volume of the local block of the massif. The paper presents an approach to simulating of a threedimensional model of rock distribution from the difficulty of drilling in the volume of a local block that is subject to explosive destruction. The results of approbation of the equipment and simulation procedure at a large mining enterprise OJSC "Uralasbest" when blast holes are drilled with roller-type drill rig are presented. As a result of the approbation of the equipment, the values of the average power consumption for the drilling of one meter of the well were set by the machine tool, the fraction of power attributable to the auxiliary operations, and the average energy intensity of the fracture (by the rotator power, without taking into account the compressor's cost for blowing the well). Based on the test results, a digital model has been developed that has made it possible to improve the quality of studies on strength properties of rocks in an experimental local block prepared for explosive destruction. Key words: Strength properties, models, rocks, properties, drilling, blast holes, equipment.
\end{abstract}

\section{Introduction}

In Russia, during the development of solid minerals deposits in large quarries, up to 1 billion tons of rocks are mined, at least $80 \%$ of which are rocky and can be destroyed only with the use of drilling and blasting methods. The effectiveness of destruction of rocks by

*Corresponding author: pochta8400@inbox.ru 
drilling and blasting is largely dependent on the correspondence of strength properties of rocks to the technical characteristics of drilling equipment and explosives. Existing methods for obtaining information on the strength of the rocks being developed are the operational additional exploration of mineral deposits, the method for determining the properties of the rocks of the massif in terms of the rock drillability index have certain certainty that should increase as the mineral deposit is mined.

The Institute of Mining of the Ural Branch of the Russian Academy of Sciences is carrying out research to improve the modeling and strength properties of rocks in the process of roller drilling blast holes in quarries. The method of obtaining information on the properties of the rock massif was first proposed by the Soviet scientist I.A. Tangayev [1] in the 70's of the XX century. Further research in this direction was developed by Russian [26] and foreign scientists [7-11].

\section{Sequence of actions for obtaining the necessary data for modeling purposes}

According to the studies [3], index of the difficulty of drilling based on the index of rock drillability, according to V.V. Rzhevsky, can be used as a criterion for evaluating rocks by strength.

To determine the difficulty of drilling index, the Institute of Mining of the Ural Branch of the Russian Academy of Sciences, in cooperation with JSC NPO Avtomatiki, developed a special set of equipment. The equipment is a system of sensors connected to the controller, which provides wireless data transfer to an external server (Fig. 1).

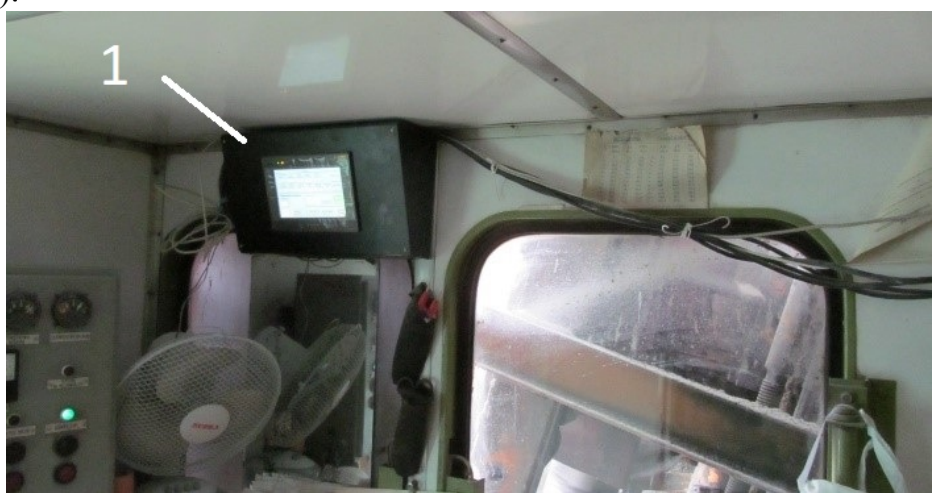

Fig. 1. The equipment installed in the cabin of the drilling rig SBSH-250MNA-32: 1- controller.

The sequence of actions performed to obtain the necessary information for the subsequent simulation of the distribution of rocks in terms of the difficulty of drilling in the volume of a local block is as follows.

Choosing a rational drilling technology and tools. Next, a roller-type drilling rig drills blast holes according to the project for drilling and blasting operations (Fig. 2). In the process of drilling blast holes, the chisel passes various strength rocks. At the same time, the sensor system measures the electric parameters of the drilling rig motors, and records the time and depth of drilling of each well. 


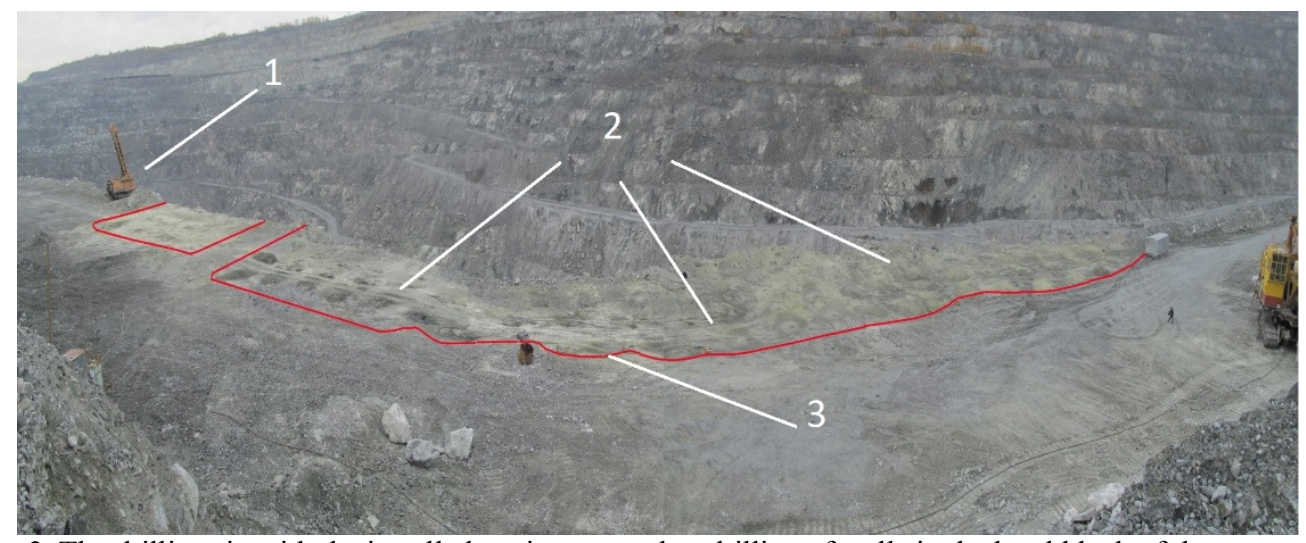

Fig. 2. The drilling rig with the installed equipment makes drilling of wells in the local block of the rock massif: 1 - drilling rig SBSH-250MNA-32; 2 - blasting wells; 3 - local block of the rock massif.

The obtained information on the parameters of the drilling process for blast holes is transferred via wireless communication to the server of the enterprise data center to calculate the drilling difficulty for each well. The calculation results are transferred to the database of the system and in the future they are used as basis for constructing of a digital three-dimensional model for the location of rocks and ores with different strengths within the boundaries of the local block of the massif.

\section{Simulation of strength properties of rocks by drilling results}

Based on the information received from the sensors, the drilling difficulty index, which objectively reflects the strength properties of the massif, is calculated. Thus, we obtain an array of data spatially distributed over each well in the local block. To build a volumetric model of rock distribution from the difficulty of drilling, it is necessary to determine the values of the index reflecting the strength properties of the rocks not only in each well, but also at points located between the wells. To solve the problem, the kriging geostatistical method [12], which is realized in the program environment $\mathrm{R}$, is the best.

At the first stage of building a three-dimensional model, the grid of the block is calculated. To do this, the block is divided into the specified elements. The size of one element is: one meter in width, one meter in length and 0.5 meters in depth. You can specify other values for the elements. However, if you make a very small grid, the calculation of the model is much longer. At the final stage, a three-dimensional model of the rock distribution from the difficulty of drilling is calculated. The result of the model is shown in Fig. 3. 


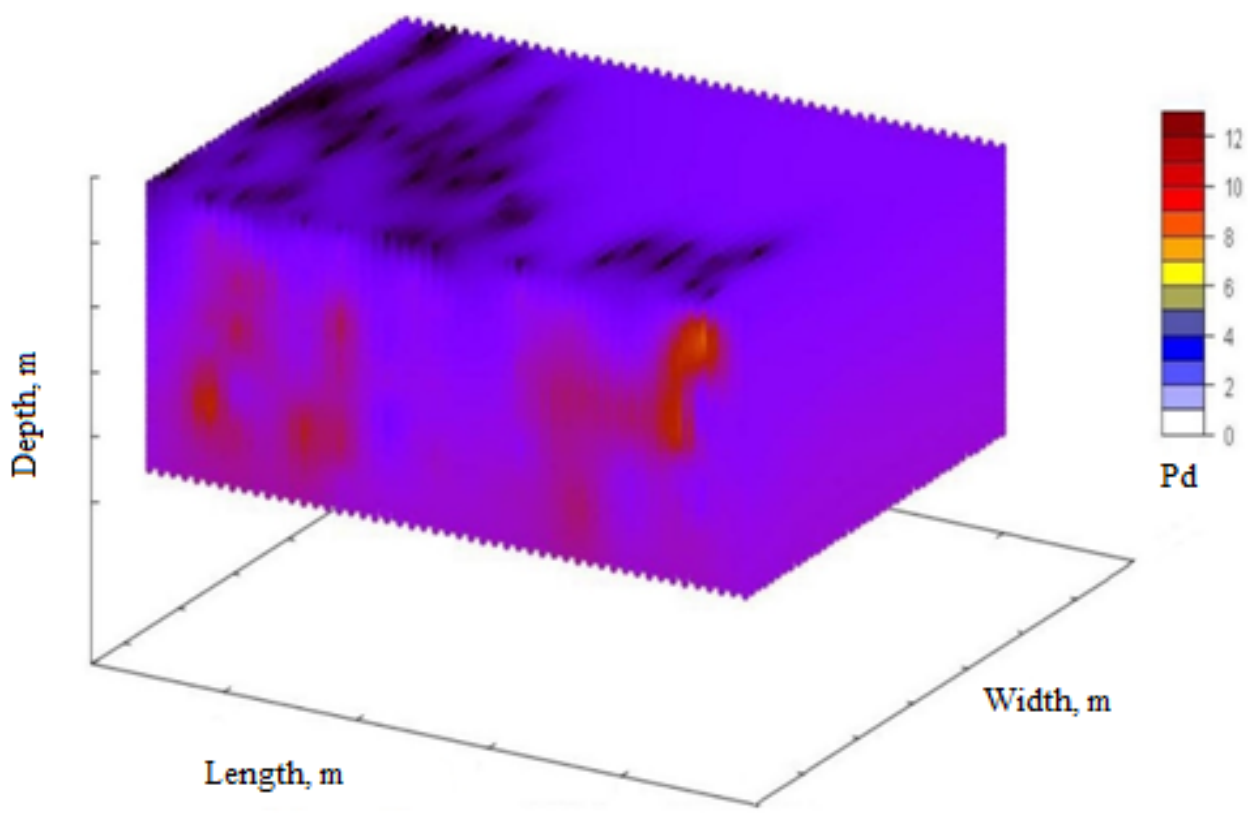

Fig. 3. Three-dimensional model of the distribution of rocks in the local block in terms of the difficulty of drilling index $\mathrm{P}_{\mathrm{d}}$.

To visualize the features of the distribution of rocks in terms of the difficulty of drilling index $P_{d}$ into the depth of the massif prepared for explosive destruction, a number of sections through $0.35 \mathrm{~m}$ are carried out in a three-dimensional model. One of these sections of the model in the direction of changing the width of the block is shown at Fig. 4.

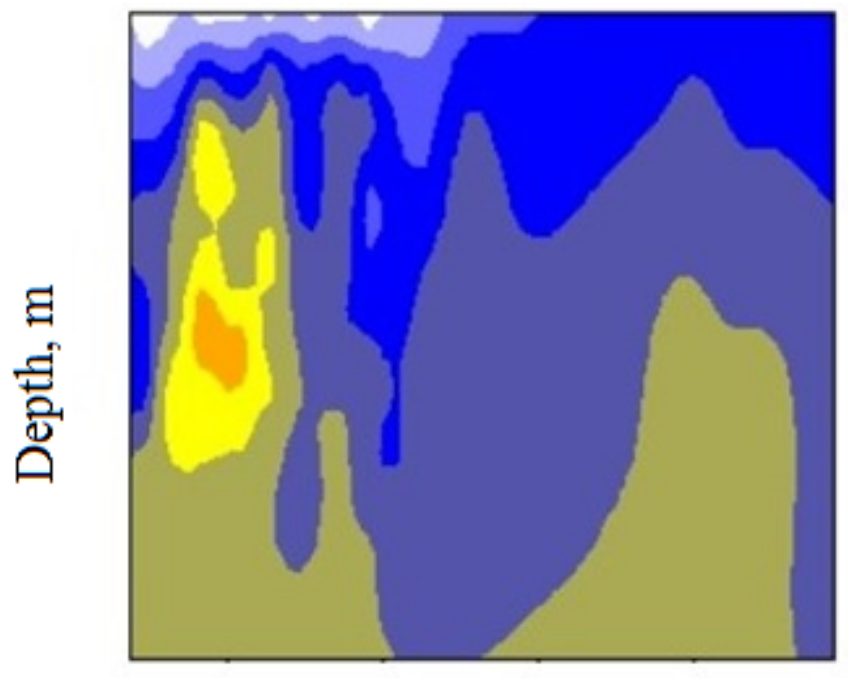

Block width, $\mathrm{m}$

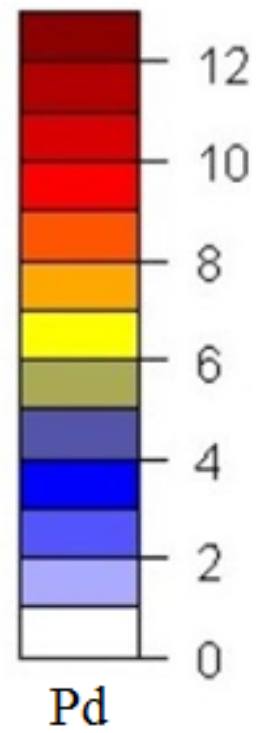

Fig. 4. Three-dimensional model direction by depth of the block. 


\section{Results and discussion}

Approbation of the equipment and simulation procedure was carried out at quarries of an OJSC "Uralasbest" large mining enterprise when blasting wells were drilled on the test block with a SBSH-250MNA-32 roller-type drill rig.

In the process of measuring the parameters of drilling at the quarries of OJSC "Uralasbest" a large amount of observations were obtained in rocks of various petrographic composition represented by chrysotile serpentinites, amorphous and schistose crescents, gabbros and diorites.

Processing of data in a special software allowed the data obtained from the machine to be translated into the values of the difficulty of drilling index $P_{d}$. Further, using the kriging method, digital models were created.

As a result of distribution of rocks in the experimental block of the massif prepared for explosion destruction simulation, it was established that there is a section of very difficult rocks with high strength (Fig. 5).

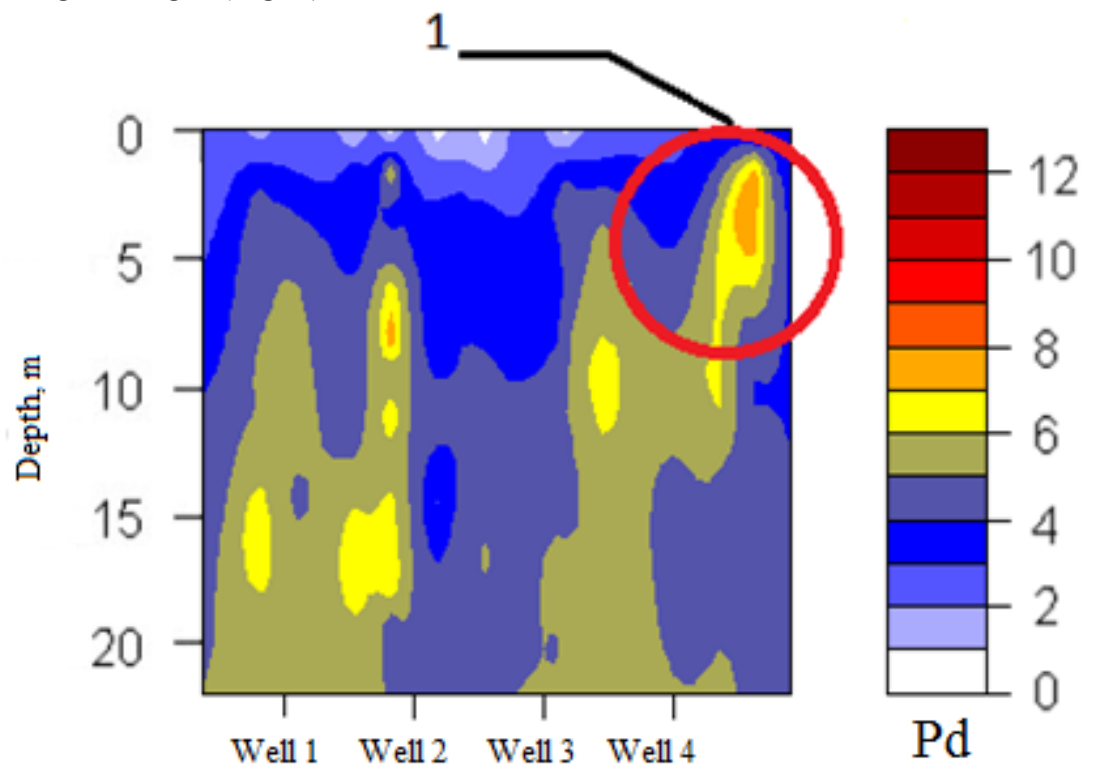

Fig. 5. Three-dimensional model direction on the difficulty of drilling index $P_{d}$ : 1- section of very difficult rocks with high strength.

After carrying out of blasting operations in the field of prospective finding of a site of rocks with the high durability there was an undestroyed site of the diorite block (fig. 6). The Institute of Mining of the Ural Branch of the Russian Academy of Sciences has developed a procedure [13] for determining the specific explosive consumption, taking into consideration the data of the simulation of the rock distribution by the difficulty of drilling index. The technique allows to adjust the charge column and the mass of explosives located in the well, in accordance with the forecast. Thus, as a result of a mass explosion, it is possible to improve the quality of crushing of the rock mass. 


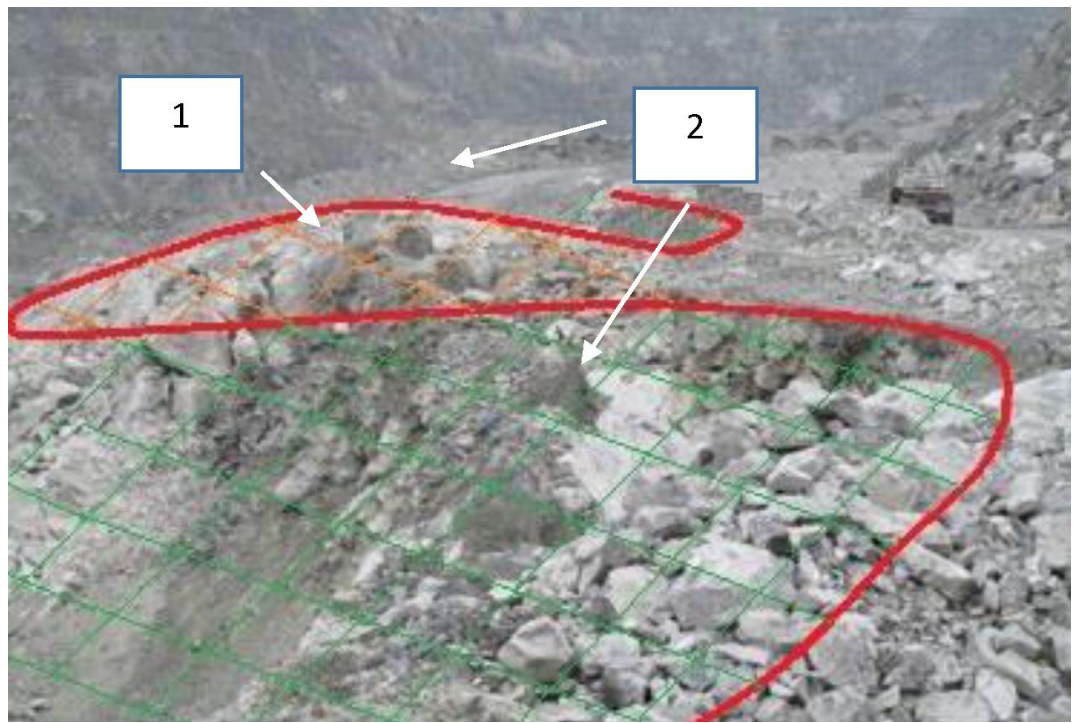

Fig. 6. Experimental site after explosion: 1-unprocessed area of diorite; 2- destroyed area of the local massif

In general, studies have shown that in the rock massifs represented by the same type of rock, the difficulty of drilling index varied widely. The main factors determining a wide range of the indicator's change were heterogeneity, intermittency of the rock massif and the influence of the zones of technological disturbance. As a result of the analysis of the results of the experimental drilling in the quarries of OJSC "Uralasbest" it was also found that the SBS-250MNA-32 drilling rig for drilling one meter of a 18-meter-long well consumes an average of $134 \mathrm{kWh}$ of electricity. Ancillary operations consume about $20 \mathrm{kWh}$ of this amount. At the same time, the energy intensity of a blast hole drilling (according to the power of the rotor without taking into account the compressor's power consumption for blowing the well to take off the products of destruction) averages $1.4 \mathrm{kWh} / \mathrm{m}$.

\section{Conclusions}

1. The technique of research of strength properties of local rock massifs in the process of drilling of blast holes is improved, based on measuring the parameters of the engine of the drilling rig. To implement the methodology, a special set of equipment was created.

2. Approbation of the device on a roller-type drilling rig was carried out at quarries of an OJSC "Uralasbest" large mining enterprise. Based on the test results, a digital model has been developed that makes it possible to accelerate the process and improve the quality of studies on the strength properties of rocks of a local block prepared for explosive destruction.

Studies carried out within the framework of the State order 007-00293-18-00, on subject No. 0405-2018-0015, No. 0405-2018-0001, project No.18-5-5-10, plus attraction of additional contractual means.

\section{References}

1. I.A. Tangayev, Drilling and Explosion of Rocks, 184 (1978).

2. B.S. Rogalsky, E.A. Shtogrin, I.S. Kushmir, Journal of mining, 7, 41 (1985).

3. S.N. Zharikov, Journal of mining, 7, 50 (2010). 
4. S.N. Zharikov, Blasting work, 111-68, 155 (2014).

5. R.I. Sukhov, Journal of mining, 3, 26 (1991).

6. PI.Sukhov, A.S. Regotunov, Subsurface resources management issues. 4 (11), 121 (2016).

7. K. Thuro, Proceedings of the World Tunnel Congress '97 materials, 1, 103 (1997).

8. N. Bilgin, S. Kahraman, 1a" International Mining Congress and Exhibition ot TurkeyIMCET, 177 (2003).

9. E. I.Luis, E. C.Luciano, Mining Technology (Trans. Inst. Min. Metall. A), 113, A 225 (2004)

10. V.C. Kelessidis, The Journal of The Southern African Institute of Mining and Metallurgy, 111, 429 (2011).

11. O.Yarali, E. Soyer, Tunnelling and underground space technology, 33, 46 (2013)

12. A.A. Saveliev, S.S. Muharamova, A.G. Pilyugin, N.A. Chizhikova Geostatistical analysis of data in ecology and nature management (with the use of package R), 120(2012).

13. S.N. Zharikov, V.G. Shemenev, V.A. Kutuev, Sustainable Development of Mountain Territories, 9, 74 (2017). 